\title{
A Psicologia na Área Rural: Os Assentamentos da Reforma Agrária e as Mulheres Assentadas
}

Psychology in Rural Areas:

The Land Reform Settlements and the Settled Women

La Psicología en el Área Rural: Los Asentamientos de la Reforma Agraria y las Mujeres Asentadas

Gislayne Cristina Figueiredo Vasquez Universidade de São Paulo
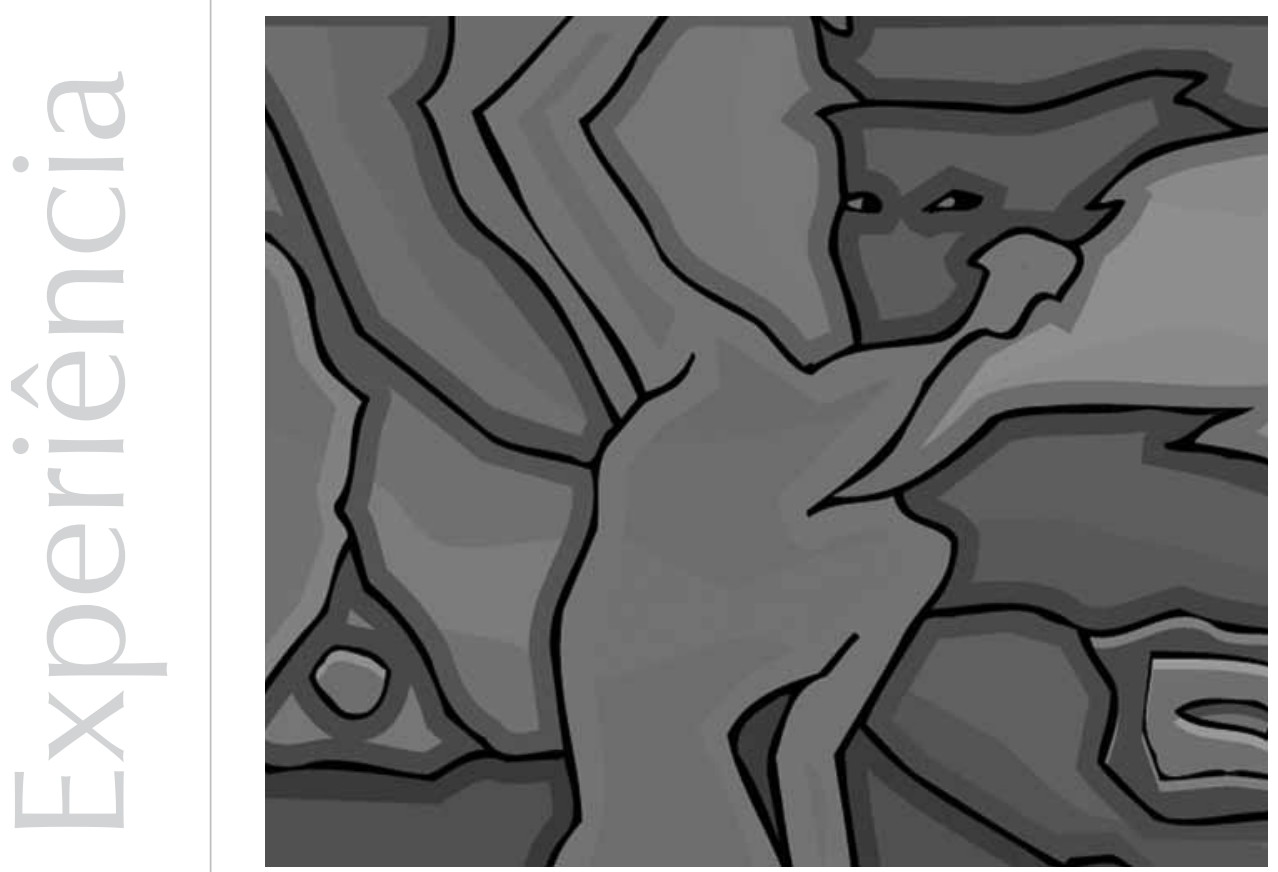
Resumo: Este trabalho é um relato de intervenção realizada pela autora quando técnica da Fundação ITESP (Fundação Instituto de Terras do Estado de São Paulo), com grupos de mulheres assentadas de São Paulo. Durante o período de um ano e meio, foram realizadas reuniões de grupo semanais, abertas, com duração de aproximadamente duas horas cada. Essas intervenções se orientaram pelos pressupostos teóricos de Pichon-Rivière e de Bleger sobre o trabalho com grupos bem como por uma técnica denominada "clube dos saberes", utilizados por terapeutas brasileiros no trabalho com pacientes psicóticos. Os grupos possibilitaram a discussão das questões de gênero nos assentamentos e tiveram como resultado um aumento na auto-estima, na autonomia e na capacidade organizativa dessas mulheres. Por outro lado, o trabalho foi dificultado, entre outros fatores, pelo desconhecimento da população rural acerca do que é Psicologia. O artigo termina tecendo considerações acerca do papel da Psicologia na área rural bem como evidencia a necessidade de nos voltarmos para o homem e a mulher do campo e para sua subjetividade.

Palavras-chave: Psicologia social. Área rural. Assentamentos. Mulheres assentadas.

Abstract: The purpose of this article is to describe the participation of the author in the ITESP Foundation (Institute of Land of the State of São Paulo - Brazil), dealing with groups of women, who are landless settlers. Weekly meetings were held during a period of 18 months. Each meeting lasted two hours and they were open to all who were willing to participate. The methods applied at the meetings were based on PichonRivière and Bleger's theories on group work. It was also applied a technique called "club of wisdoms", used by Brazilian therapists when working with psychotic patients. Many themes and questions were brought up to discussion, all of them dealt with their reality in the settlements. Positive results were observed, for among the women there was an increase of self-esteem and autonomy as well as in their capacity of organization. On the other hand, in these rural areas, there is a lack of knowledge of what Psychology is, and this fact hinders the job. The article concludes with some considerations on the role of psychology in rural areas, and makes evident the need to give special attention to the rural man and woman and to their subjectivity. Keywords: Social psychology. Rural area. Landless settlements. Settled women.

Resumen: Este trabajo es un relato de intervención realizada por la autora cuando técnica de la Fundación ITESP (Fundación Instituto de Tierras del Estado de Sao Paulo), con grupos de mujeres asentadas de Sao Paulo. Durante el período de un año y medio, fueron realizadas reuniones de grupo semanales, abiertas, con duración de aproximadamente dos horas cada. Esas intervenciones se orientaron por los presupuestos teoréticos de Pichon-Rivière y de Bleger sobre el trabajo con grupos así como por una técnica denominada "clube dos saberes" (club de los conocimientos), utilizados por terapeutas brasileños en el trabajo con pacientes sicóticos. Los grupos posibilitaron la discusión de las cuestiones de género en los asentamientos y tuvieron como resultado un aumento en la autoestima, en la autonomía y en la capacidad organizativa de esas mujeres. Por otro lado, el trabajo fue dificultado, entre otros factores, por el desconocimiento de la población rural acerca de lo que es Psicología. El artículo termina tejiendo consideraciones acerca del papel de la Psicología en el área rural así como evidencia la necesidad de que nos dirijamos al hombre y la mujer del campo y a su subjetividad.

Palabras clave: Psicología social. Área rural. Asentamientos. Mujeres asentadas.

Este artigo visa a expor uma intervenção realizada junto a mulheres que vivem em assentamentos da reforma agrária no Estado de São Paulo, efetivado quando trabalhamos como técnica da Fundação Instituto de Terras do Estado de São Paulo (ITESP), junto a uma equipe multidisciplinar de campo. A relevância deste trabalho advém do fato de que a área rural tem reafirmado sua importância na sociedade brasileira, seja através de debates acadêmicos, seja através da veiculação de notícias sobre os movimentos sociais do campo na mídia. No entanto, a Psicologia em nosso país tem pouca intimidade com a área rural.

O trabalho com as mulheres também se justifica em função de sofrerem uma série de violências decorrentes de uma relação de gênero desigual, sendo que vários estudos comprovam que as mulheres da área rural, em comparação com as da zona urbana, são ainda mais submetidas a agressões físicas, sexuais e psicológicas bem como às várias situações de exclusão econômica e de dificuldade de acesso a políticas públicas voltadas para esse segmento. 
A experiência que ora relatamos foi realizada por um ano e meio, tendo sido proposto para três assentamentos e efetivamente assumido por deles. A metodologia utilizada constituía na realização de grupos abertos, segundo os pressupostos dos grupos operativos, que se realizavam uma vez por semana, com duração de aproximadamente duas horas.

O objetivo da intervenção era o de trabalhar as questões subjetivas, partindo de uma atividade concreta, que valorizasse o saber das próprias mulheres. Esperava-se com isso uma mudança na forma como as mulheres se relacionam com o próprio grupo e consigo mesmas bem como uma melhora na autoconfiança, na auto-estima e na autonomia das participantes.

Outrossim, buscamos também contribuir com o debate acerca das possibilidades de intervenção em Psicologia, com reflexões que estimulem a saída do profissional dos consultórios e que fomentem sua inserção no cotidiano das pessoas, contemplando assim o compromisso social da Psicologia e destacando um campo de trabalho que, até o presente momento, está relegado a segundo plano.

\section{A área rural e sua importância no Brasil}

Ultimamente, estudos acadêmicos têm chamado a atenção para o fato de o Brasil não ser tão urbano - ou ser mais rural do que se propalava. A visão oficial considera que o País tenha atingido um grau de urbanização de $81,2 \%$, segundo o Censo Demográfico de 2000 (Veiga, 2003). Para Veiga, no entanto, os critérios adotados para se calcular essa taxa são únicos no mundo: considera-se urbano a sede de qualquer Município, vila ou distrito, independentemente de suas características.

Refazendo esse cálculo com os parâmetros utilizados por outros países do mundo (tamanho populacional do Município, densidade demográfica e localização), o referido autor redimensiona o tamanho e a importância da área rural brasileira bem como o grau de urbanização do País. Chega à conclusão que 80\% dos Municípios brasileiros são rurais, onde residem 30\% da população. Além disso, outros $10 \%$ dos Municípios, que abrigam 13\% da população, são vilas "rururbanas", que poderão ou não se transformar em cidades. Assim, os Municípios urbanos do País abrigam 57 \% dos brasileiros, enquanto entre 30 a $43 \%$ vivem na área rural, ocupando um espaço entre 80 e 90\% do território nacional (Veiga, 2003).

Compondo esse universo de indivíduos e famílias que vivem no meio rural e organizam sua vida em função do campo, estão aquelas famílias de trabalhadores rurais que vivem em assentamentos de reforma agrária.

Há uma grande dificuldade de se encontrar informações precisas sobre a quantidade de assentamentos no País hoje. Os dados são fragmentários e às vezes conflitantes. Números do Ministério do Desenvolvimento Agrário (MDA) indicam que 769.400 famílias foram assentadas no período de 1995 a 2005, mas não fazem referência aos períodos anteriores (Núcleo de Estudos Agrários e Desenvolvimento Rural [NEAD], 2006a). Já Coletti (2002), em uma interessante tabela que compara os números veiculados por movimentos sociais pelo governo e por entidades de pesquisa, citando dados do MDA e do Instituto de Colonização e Reforma Agrária (INCRA), reporta que, entre 1985 e 1994, foram assentadas 152.000 famílias. Esses números servem para nos dar a idéia de que as famílias assentadas hoje podem chegar a um milhão.

Várias pesquisas sobre essa população têm sido realizadas pelas mais diversas áreas da ciência. A gama de estudos vai desde questões de produtividade, passando 
"Mesmo a pior reforma agrária ainda é capaz de proporcionar casa, comida e trabalho" (D'Incao \& Roy, 1995; Fernandes, 1996; ITESP, 2000; Leite, Heredia, Medeiros, Palmeira, \& Cintrão, 2004; Oliveira, 1999). pela definição de agricultura familiar, sustentabilidade, agroecologia, histórico das lutas e movimentos sociais, violência no campo e conflitos agrários e fundiários, perfil dos assentados, cultura, linguagem, modo de vida, costumes e redes e relações sociais nos assentamentos, chegando à importância da reforma agrária, explicitada na frase atribuída a José Gomes da Silva: "Mesmo a pior reforma agrária ainda é capaz de proporcionar casa, comida e trabalho" (D'Incao \& Roy, 1995; Fernandes, 1996; ITESP, 2000; Leite, Heredia, Medeiros, Palmeira, \& Cintrão, 2004; Oliveira, 1999).

Se há uma grande quantidade de estudos acadêmicos sobre a importância e as características dos assentamentos em seus aspectos econômicos, produtivos e sociais, pode-se observar, por outro lado, que há poucos estudos sobre o desenvolvimento e a vivência da subjetividade dentro dos assentamentos. A própria Psicologia, como ciência nascida dos grandes centros urbanos, tem reservado um lugar secundário para a área rural (e os assentamentos) como espaço de pesquisa e intervenção na produção e vivência de subjetividades (Albuquerque, 2002). Recentemente, a Psicologia social, como área específica da Psicologia, tem voltado suas atenções para a área rural e realizado alguns estudos, principalmente sobre os indivíduos que participam de movimentos sociais do campo, a função da mística nesses movimentos, as características da população rural e/ou assentada, o impacto de políticas sociais na subjetividade de segmentos específicos e a educação do campo, entre outros (Albuquerque, Lobo, \& Raimundo, 1999; Brancaleoni, Pinto, \& Casagrande, 2003; Lara, 2005; Leite \& Dimenstein, 2006).

Nesse trabalho, partimos da premissa de que os assentamentos se constituem em espaços de reprodução da vida dos indivíduos, sendo, ao mesmo tempo, o lugar de constituição de relações de amizade e companheirismo, de afeto e parentesco (família), de moradia, de trabalho, de lazer, enfim, local de construção e reconstrução da subjetividade e da identidade do assentado.

\section{As mulheres e a terra}

Segundo Nobre, Siliprandi, Quintela e Menasche (1998), se, desde os anos 50, se debate a agricultura familiar e a reforma agrária, pouco se discute ou se detém o olhar sobre as pessoas que vivem na área rural, seus sonhos e desejos.

De acordo com o Relatório de Desenvolvimento Humano do Programa das Nações Unidas para o Desenvolvimento (PNUD/ONU, 1997), "nenhuma sociedade trata as mulheres com igualdade em relação aos homens". A questão de gênero, por nós entendida como construção histórica e social que determina os papéis, identidades e relações que cada um deve assumir dentro da sociedade, também se faz presente no campo, e a mulher da área rural sofre ainda mais com a invisibilidade do que a da área urbana (Faria \& Nobre, 1997; NEAD, 2006b).

Um estudo do Instituto Brasileiro de Geografia e Estatística (IBGE, 2002) revela claramente a situação da mulher no usufruto dos rendimentos da lavoura: apesar de trabalhar muito nas áreas rurais, cerca de $55 \%$ das mulheres não têm nenhum tipo de rendimento, isto é, não recebem remuneração financeira de qualquer espécie.

As mulheres da área rural também são mais submetidas à violência do que as da área urbana. A Organização Mundial de Saúde (OMS) compilou dados de vários países que indicam que a violência doméstica (física, sexual e psicológica) é maior em populações rurais do que em populações urbanas. No caso do Brasil, 37\% das mulheres da zona rural sofrem violência física ou sexual perpetradas pelos 
seus companheiros, contra $29 \%$ da zona urbana (OMS, 2005).

A situação de exclusão econômica e de maior vitimização a que está submetida a mulher da zona rural pode ser explicada pelas relações de gênero mais desiguais no campo. A família patriarcal e a divisão de papéis de gênero mais definido, em que o homem tem o poder de decidir a vida e o dinheiro das mulheres, filhas e filhos menores, ainda são aceitas sem grandes questionamentos pelas famílias de trabalhadores rurais e são, muitas vezes, reproduzidas pelas próprias mulheres (NEAD, 2006b; Nobre et al., 1998).

No caso dos assentamentos, tal fato também se repete. Neles, da mesma forma que na área rural como um todo, as mulheres possuem um papel essencial na organização e na sustentabilidade de todo o grupo social, ao mesmo tempo em que constituem um segmento mais vulnerável às dificuldades sociais e econômicas (Nobre et al., 1998).

Nos assentamentos do País, as mulheres correspondem a cerca de $46 \%$ da população assentada (Leite et al., 2004). No entanto, apenas $15 \%$ dos lotes têm mulheres como titulares principais, e é sabido que, mesmo entre essas, nem sempre são elas a cuidarem das economias, como em geral acontece na zona rural (Albuquerque et al., 1999; Leite et al., 2004; Nobre et al, 1998). É curioso observar que a porcentagem de mulheres que vivem na zona rural é menor do que a de homens, em um fenômeno inverso ao que ocorre na zona urbana. A situação de vida da mulher na área rural faz com que a migração para a zona urbana seja mais atraente para elas do que para os homens (NEAD, 2006b; Nobre et al., 1998).

Podemos perceber nas histórias trazidas pelas mulheres que, se por um lado elas são parte ativa e essencial na produção agrícola, sendo responsáveis por boa parte da riqueza gerada nos assentamentos, por outro, estão sujeitas a um sem número de situações que ferem seus direitos, situações essas perpetradas tanto por aqueles que convivem com elas quanto por órgãos públicos que, em tese, deveriam prestar-Ihes assistência e garantir os seus direitos e que, muitas vezes, não a reconhecem como trabalhadora rural. Assim, em virtude da divisão sexual do trabalho marcante na área rural, que nomeia o trabalho feminino como "ajuda", as mulheres realizam um sem-número de tarefas que produzem renda, tanto agrícola quanto não agrícola, sem a menor visibilidade no tocante ao reconhecimento de sua contribuição e relevância (NEAD, 2006b; Nobre et al., 1998).

Entre as atividades agrícolas realizadas pelas mulheres nos assentamentos acompanhados, há o trabalho constante na lavoura, em todas as suas fases (preparo da terra, plantação, cultivo, manutenção e trato, colheita, etc.), o trabalho com criações comerciais (gado, pequenos animais) e a responsabilidade pela produção de subsistência (horticultura, fruticultura, pequenos animais para consumo, como frangos e porcos). Apesar de participar intensamente de todo o trabalho agropecuário, a mulher em geral não participa da venda nem das decisões sobre a destinação do dinheiro ganho, fruto da comercialização.

Quanto às atividades não agrícolas realizadas, estão o artesanato e pequenos trabalhos manuais, geradores de renda complementar que, muitas vezes, é reinvestida na agricultura. Além dessas tarefas, as mulheres realizam todo o trabalho de cuidado da casa, liberando o homem para o trabalho na roça, o que constitui mais uma estratégia de aumento da produtividade do lote.

\section{Uma proposta de intervenção da Psicologia na área rural}

Neste trabalho, realizado como técnica de campo da Fundação Instituto de Terras do 
Estado de São Paulo, procuramos voltar nosso olhar para a situação das mulheres nos assentamentos, suas características e sua subjetividade através de uma intervenção que procurasse ao mesmo tempo revelar e reorganizar a auto-estima das mulheres atendidas. Para isso, utilizamos uma técnica de intervenção em grupo baseada nas teorias de Pichon-Rivière (1994) e Bleger (2001) bem como uma prática usada por terapeutas brasileiros na intervenção junto a pacientes psicóticos (Serviço de Saúde Cândido Ferreira, 2003). Essa forma de intervenção, denominada "clube dos saberes", tem como vantagem lidar com a subjetividade dos indivíduos partindo do concreto, utilizando a realização de uma tarefa conjunta como suporte para a emergência de conteúdos verbais. No caso, a atividade concreta escolhida pelas próprias mulheres foi ensinar e aprender trabalhos manuais.

Sem desconsiderar as ressalvas feitas às teorias que embasaram a construção da proposta ora relatada, quais sejam, de que por vezes assumem uma leitura da realidade e da intervenção higienista e profilática (França, 2005), procuramos, a partir da técnica dos grupos operativos, construir uma intervenção que não só trabalhasse com as questões subjetivas mas que também contemplasse a realidade cotidiana dos assentamentos, com suas relações instituídas, intervindo nas atividades práticas e na divisão de papéis tida como natural, valorizando a compreensão de que a atuação da Psicologia é sempre política (Guirado, 1987). Nesse sentido, partimos da premissa que o indivíduo constrói seu próprio conhecimento e reconstrói sua subjetividade na medida em que realiza a tarefa, momento esse em que simultaneamente reflete e questiona posições estereotipadas, problematiza as certezas adquiridas e, através do contato com outros seres humanos, constrói um novo esquema referencial para a compreensão do mundo e de si mesmo (Bleger, 2001; PichonRivière, 1991).
O trabalho se desenvolveu por um ano e meio (do final de 2002 até o início de 2004), com reuniões semanais de duração aproximada de 2 horas. Inicialmente proposto a três grupos de mulheres em três assentamentos diferentes (Porto Feliz, Fazenda Ipanema área I e área II), foi assumido pelos grupos de mulheres de Porto Feliz e da Fazenda Ipanema área II. Os grupos, que eram abertos, contavam com a participação de 20 mulheres em média. A tarefa (tema a ser discutido e atividade manual a ser realizada) para a reunião era definida em conjunto pelo psicólogo e pelas participantes.

Respeitando o princípio de que cada grupo "cria seus objetivos e faz as suas descobertas através da ativação daquilo que existe em cada ser humano de riqueza e experiência" (Bleger, 2001, p. 76), intencionamos trabalhar a auto-imagem e a auto-estima, com a conseqüente reorganização na subjetividade das participantes, ao valorizar a forma como elas lidam com o seu próprio conhecimento. Esperava-se como resultado uma mudança na relação com o seu meio, com as pessoas a sua volta, uma melhora na autoconfiança e um aumento na autonomia das assentadas.

Inicialmente, foi feito um "mapeamento dos saberes", ou seja, um levantamento conjunto daquilo que cada uma das mulheres conhecia e estava disposta a dividir com as outras. A realização dessa tarefa teve a duração de duas reuniões em ambos os grupos, oportunidade em que também foram discutidos os assuntos que poderiam ser "conversados" nos encontros, concomitantemente com a aprendizagem dos trabalhos manuais, bem como a data da semana em que se dariam as atividades, a periodicidade, a duração; enfim, foi feito o enquadramento da intervenção.

Segundo o que foi definido no enquadre, cada reunião era conduzida pela assentada que iria ensinar a atividade manual, com o apoio da coordenação, papel que foi 
assumido pela psicóloga. A coordenação buscava atuar muito mais como um "COpensador" (Pichon-Rivière, 1991, p. 92), ou seja, facilitar a comunicação e o diálogo, evitando o choque frontal e explicitando os implícitos, possibilitando que o grupo pudesse chegar a uma nova compreensão sobre si mesmo.

Com o tempo, e com o intuito de fomentar a auto-organização e o trabalho em grupo de forma autônoma, bem como de fomentar a independência em relação ao trabalho do psicólogo, a partir da discussão com as assentadas e a assunção de um novo enquadre, a participação deste técnico na reunião se tornou quinzenal. Tal arranjo se deu paralelamente ao surgimento das chamadas lideranças funcionais, participantes dos grupos que assumiam, alternadamente, a condução da tarefa. As mulheres passaram então a convidar outros profissionais em semanas alternadas (médicos, enfermeiras, assistentes sociais), visando a discutir as questões surgidas no grupo, bem como passaram a discutir a sua própria organização e a realização de trabalhos conjuntos.

Os conteúdos que emergiram nas reuniões versavam sobre relações entre gênero, cuidados com os filhos, relações entre as mulheres, violência doméstica, serviços públicos de atenção à mulher e à família e direitos sociais, entre outros.

Com o desenvolvimento do trabalho, houve a manifestação de resistências e ansiedades bem como momentos em que ocorreram choques frontais, nos quais o grupo teve seu processo de desenvolvimento dificultado. Também ocorreram momentos denominados por Pichon-Rivière (1991) de "sabotagem", em especial com a intervenção de uma profissional da municipalidade, que tentou aproximar-se do grupo visando a usar o espaço para a realização de oficinas dirigidas obrigatórias de um programa social. A partir dessa intervenção, surgiram vários conflitos, e as assentadas optaram por continuar o grupo na forma inicialmente combinada, alterandose o dia do encontro.

A análise da intervenção indicou um aumento da auto-estima e da autonomia dessas mulheres bem como da capacidade de lutarem por seus direitos. Sinais dessa mudança puderam ser notados desde a forma de elas se arrumarem até o fato de terem se tornado mais ativas dentro do assentamento, levando os assentados a discutirem novos assuntos e recolocando na pauta a relação entre homens e mulheres.

O aumento da auto-estima e da autonomia, bem como a emergência de um novo esquema referencial grupal, pôde ser sentido também no aumento da solidariedade entre as participantes e as mulheres de fora do grupo: as do grupo passaram a dar um suporte social às outras em casos de violência doméstica, em casos de necessidade de orientações em cuidados com saúde e em outros direitos da mulher.

O incremento na mobilização feminina teve reflexos nos equipamentos sociais e comunitários, como a instalação de um parquinho na escola de um dos assentamentos, obtido pelas mulheres junto a entidades da sociedade civil, e a criação de uma comissão independente de mulheres em outro, para discutir junto ao prefeito e demais autoridades públicas municipais questões de saúde. Além disso, houve um contato maior entre as agências que intervêm no assentamento - saúde, Prefeitura, Governo estadual, por iniciativa das assentadas.

Os grupos também possibilitaram uma reflexão sobre o papel da mulher no assentamento, desde sua criação até o momento atual, e serviram como espaço de emergência e elaboração de temas como a relação com os homens, o papel feminino no meio rural, a 
sexualidade, a violência doméstica e sexual, o sexismo. O trabalho de reflexão dentro dos grupos permitiu uma quebra na estereotipia e uma problematização do cotidiano em comum, em especial do papel que era tido como natural pelas mulheres. Considerando o fato de que, através da introjeção dos papéis dos outros integrantes na realização da tarefa do grupo, os indivíduos vão retificando a sua própria estereotipia, a figura da psicóloga representou um contraponto ao papel assumido pelas mulheres no assentamento, em geral homogêneo dentro dos grupos acompanhados. Isso possibilitou uma reflexão dos outros lugares socialmente aceitos para o papel do feminino e permitiu uma reflexão sobre as relações de gênero como social e historicamente construídas.

Também pôde ser notada uma modificação na relação das mulheres com os seus direitos: se antes havia, de forma subjacente, uma compreensão dos serviços sociais como um favor do Estado ou de outras entidades assistenciais, elas passam a se ver de forma mais ativa, como cidadãs detentoras de direitos que podem ser discutidos, demandados e problematizados, direitos esses como saúde, acesso à previdência social, justiça gratuita e respeito à integridade física e psíquica, entre outros.

O aumento da renda direta e indireta de boa parte das mulheres que participaram do grupo, bem como a possibilidade de geração de renda para algumas que eram totalmente desprovidas desta, foi outro aspecto positivo.

Por outro lado, foram encontradas algumas dificuldades para o desenvolvimento do trabalho. Uma delas, que está diretamente relacionada com as contingências do trabalho institucional, é a dificuldade de se construir, dentro do trabalho multidisciplinar pretendido pela Fundação Instituto de Terras do Estado de São Paulo (ITESP), um olhar voltado para as questões sociais e subjetivas. Se, por um lado, havia um grande apoio institucional e da equipe técnica bem como um reconhecimento acerca da importância do trabalho e de seu resultado, há que se pontuar que os profissionais, em geral, possuem uma formação agronômica, e a própria instituição tem um olhar mais voltado para a produtividade; assim, quando a questão social aparece, é marcada por um viés assistencialista. Há também um desconhecimento do papel e das especificidades do trabalho do psicólogo social, que ora é confundido (tanto por técnicos quanto pela população atendida) com um assistente social, ora é confundido com um profissional da saúde devido à tradição mais forte da Psicologia clínica em nosso meio.

A fragilidade decorrente das contingências institucionais também pôde ser sentida no motivo do fim do trabalho: com a saída desta psicóloga, não havia outro profissional no quadro técnico com perfil semelhante para continuar a intervenção; com isso, os grupos continuaram funcionando, de forma autônoma, por um curto período de aproximadamente três meses, em um caso, e de cerca de cinco meses, no outro, tendo se fragmentado posteriormente ou se reunido de forma eventual para tratar de questões pontuais após esse período.

Assim, um dos pontos negativos observados na aplicação dessa técnica de intervenção no assentamento foi o fato de a psicóloga ter assumido o trabalho sozinha, sem a presença de um observador que auxiliasse na coordenação das reuniões, o que, por vezes, dificultou a percepção de certos processos subjacentes, resultando em atraso para o desenvolvimento do grupo e em prejuízo para a continuidade do mesmo.

Outro grande dificultador do trabalho desenvolvido junto às assentadas é a 
fragilidade a que estão submetidos os grupos e as organizações comunitárias construídos pelas mulheres. Em grande medida, essa fragilidade ocorre em função da pouca alternativa de geração de renda, pois muitas das atividades pretendidas e planejadas de forma autônoma pelas mulheres não se realizavam devido à falta de recursos financeiros, o que causava um certo grau de desânimo e de desmobilização.

Temos que considerar ainda que a relação da zona rural com a zona urbana se dá de uma forma dialética, e, no caso dos assentados, em especial com o centro urbano mais próximo, essa relação é bastante intensa e importante. Os assentados se relacionam com os centros urbanos para comprar bens, vender, ir a serviços de saúde, sindicatos, eventos de lazer ou religiosos, havendo um intenso intercâmbio cultural entre eles (Leite et al., 2004). Assim, a falta de recursos financeiros é agravada pela ausência de equipamentos sociais e de lazer no campo, ausências que reforçam a visão do meio rural somente como espaço de trabalho, dependente da zona urbana, o que gera muitos conflitos, carências e sentimentos de inferioridade e impotência, que causam o adoecimento psíquico.

Há muito que se caminhar para assegurar a melhoria de vida dessas populações, especialmente no caso das mulheres. Ações afirmativas voltadas para sua valorização, empoderamento e reconhecimento, como a implementação de políticas públicas que preconizem ações voltadas para maior participação e organização, o aumento das alternativas produtivas, a valorização de seu papel na agricultura familiar e no gerenciamento da produção e da renda agrícola são essenciais para que elas assumam uma posição de maior eqüidade nas relações sociais, políticas, econômicas e de gênero no campo brasileiro.

\section{Reflexões acerca da Psicologia na área rural}

São muitos os desafios e as possibilidades de inserção da Psicologia na área rural. Considerando que boa parte da população brasileira vive ou teve sua subjetividade constituída na área rural e que só recentemente a Psicologia tem mostrado interesse por essa área, dá para se ter idéia da grandeza da demanda e do tamanho da tarefa que se tem pela frente, se quisermos sanar a dívida social que temos nesse campo. Hoje já há um certo número de psicólogos acadêmicos que desenvolvem seu trabalho na área rural, em especial nos assentamentos. No entanto, há poucos profissionais atuando, seja como clínicos, seja como psicólogos sociais/comunitários.

Outrossim, a formação do psicólogo é majoritariamente, para não dizer exclusivamente, voltada para o homem urbano, e a área rural não é percebida como um campo fértil para a Psicologia. Como a maioria das ciências que não participaram das discussões mais recentes sobre o meio rural, acaba, por um lado, considerando-o com desconfiança, e, por outro, tendo uma visão romantizada sobre a vida no campo. Há a necessidade de uma formação mais específica na graduação, que inclua estágios rurais, a exemplo do que fazem outras profissões, e que discuta e absorva os aportes e conceitos dados por outras ciências, como cidadania, cultura, territorialidade e sua importância na formação da identidade/ subjetividade.

A pequena presença do psicólogo na área rural faz com que as possibilidades de intervenção e a profissão em si sejam desconhecidas da população que, como já dissemos anteriormente, ora nos confunde com o médico, ora nos confunde com o assistente social. 
Cabe ressaltar que o trabalho do psicólogo na área rural, seja clínico, seja comunitário, tem grandes especificidades e se dá de forma diferenciada: a ausência de equipamentos públicos e a cultura do homem rural resultam em diferenças na forma de atendimento; assim, a intervenção pode se dar em locais não usuais, como embaixo de uma árvore, ou em um galpão de armazenamento da safra. A cultura do meio rural, significativamente mais machista do que a da zona urbana, faz com que a aproximação da clientela atendida se dê de uma forma diferenciada, lenta e cuidadosa: no caso das mulheres, muitas demonstravam o desejo de participar, ficavam de longe olhando, mas somente se sentiam autorizadas a entrar para o grupo após uma visita domiciliar, com um convite na presença do marido, que então estaria ciente do fato de ser uma reunião "de mulheres", e cuja ausência de oposição manifestava concordância com o fato de a companheira participar da atividade.

O psicólogo também deve ter em mente que vai desenvolver seu trabalho com uma clientela territorialmente adscrita, que inclui uma diversidade imensa de casos e de situações psicológicas diferentes, com complexidades variadas. Obviamente, o psicólogo não vai atender todos os casos, em especial se for um psicólogo social, pois corre o risco de perder o foco de sua intervenção. No entanto, o profissional que pretenda trabalhar com uma clientela territorialmente adscrita deve ter uma formação generalista suficiente para dar uma orientação e um encaminhamento adequado. Em alguns casos, por questões éticas, há a necessidade de se dar um atendimento mínimo antes de encaminhar a pessoa para outro profissional ou outro serviço.

Um outro campo de ação para o psicólogo na área rural é o apoio aos movimentos sociais.
A passagem por um movimento social de luta pela terra constitui um espaço privilegiado para a reorganização da subjetividade do indivíduo participante do movimento, incluindo aí as mulheres (Silva, 2004). Caldart e Kolling (1997, p. 237) vão dizer que o movimento social

...é um espaço social de transformação das pessoas: através da luta coletiva, excluídos viram cidadãos, e, se o olhar, que antes não se desprendia do chão, aos poucos se eleva, é capaz de encontrar outro olhar refletindo nele o brio de quem passou a acreditar que pode ser sujeito da história...

Se, por um lado, a luta pela terra pode significar novas configurações nas relações de gênero, em especial no acampamento, que é o local onde a luta se acirra, essas novas configurações nem sempre se transportam para a vivência no momento posterior, ou seja, elas nem sempre se traduzem em uma melhora efetiva da vida da mulher após o assentamento (Leite \& Dimenstein, 2006; Pavan, 1998; Silva, 2004).

Cabe observar que as entidades públicas e muitas vezes os movimentos sociais dão maior ênfase ao aspecto da produção e da atividade econômica, esquecendo-se de que

\footnotetext{
...através de sua atividade, os seres humanos entram em determinadas relações entre si e com as coisas, além da mera vinculação técnica com a tarefa a realizar, e esse complexo de elementos subjetivos e de relação constitui o seu fator humano mais específico. (Bleger, 2001, p. 59)
}

A Psicologia deve chamar a atenção para o homem e a mulher do campo, enfatizando a necessidade de cuidar desses sujeitos e de suas subjetividades, o que contribuiria para a implementação de políticas públicas que os focalizassem com as suas especificidades. 
Assim, concluímos este trabalho ressaltando a importância de nos voltarmos mais para as questões subjetivas na área rural e nos assentamentos, pois, como pudemos observar, alterações na subjetividade têm reflexo em todas as áreas da vida no assentamento, desde a produção até as relações sociais, e causam um impacto considerável na melhoria de vida dos assentados. 


\section{Gislayne Cristina Figueiredo Vasquez}

Psicóloga, doutora em Psicologia pela Faculdade de Filosofia, Ciências e Letras de Ribeirão Preto - Universidade de São Paulo, Ribeirão Preto, SP - Brasil.

\section{Endereço para envio de correspondência:}

Rua Adalberto Panzan, 300, Boa Vista, Sorocaba - SP, CEP: 18085-844

E-mail: gislaynefigueiredo@usp.br

Recebido 26/09/2008, Reformulado 12/05/2009, Aprovado 20/05/2009

\section{Referências}

Albuquerque, F. J. B., Lobo, A. L., \& Raimundo, J. S. (1999). Análise das repercussões psicossociais decorrentes da concessão de benefício rurais. Psicologia: Reflexão e Crítica, $12,503-519$.

Albuquerque, F. J. B. (2002). Psicologia social e formas de vida rural no Brasil. Psicologia: Teoria e Pesquisa, 18(1), 37-42.

Bleger, J. (2001). Temas de psicologia: entrevistas e grupos. São Paulo: Martins Fontes.

Brancaleoni, A. P. L., Pinto, J. M. R., \& Casagrande, L. D. R. (2003). Do rural ao urbano: o processo de adaptação de alunos moradores de um assentamento rural à escola urbana. Perspectiva, 99(27), 51-63.

Caldart, R. S., \& Kolling, E. J. (1997). O MST e a educação. In J. P. Stédile, A reforma agrária e a luta do MST. Petrópolis, RJ: Vozes.

Coletti, C. (2002). Avanços e impasses do MST e da luta pela terra no Brasil nos anos recentes. In J. Seone, Movimientos sociales y conflictos en America Latina. Buenos Aires: CLACSO.

D'Incao, M. C., \& Roy, G. (1995). Nós cidadãos: aprendendo e ensinando a democracia. Rio de Janeiro: Paz e Terra.

Faria, N., \& Nobre, M. (1997). Gênero e desigualdade. São Paulo: SOF.

Fernandes, B. F. (1996). MST: formação e territorialização. São Paulo: Hucitec.

França, I. G. (2005). Reflexões acerca da implantação e funcionamento de um plantão de emergência em saúde mental. Psicologia: Ciência e Profissão, 25(1), 146-163.

Guirado, M. (1997). Psicologia institucional. São Paulo: EPU.

Instituto Brasileiro de Geografia e Estatística. (2002). Pesquisa de Orçamentos Familiares - POF 2002/2003. Recuperado em 15 de maio de 2007, de http://www.ibge.gov.br/ home/ estatistica/populacao/condicaodevida/pof/2002analise

Fundação Instituto de Terras do Estado de São Paulo. (2000). Cultivando sonhos: caminhos para a assistência técnica na reforma agrária. São Paulo: Autor.

Lara Jr., N. (2005). A mística no cotidiano do MST: a interface entre religiosidade popular e política. Dissertação de Mestrado, Departamento de Psicologia Social, Pontifícia Universidade Católica de São Paulo, São Paulo.
Leite, S., Heredia, B., Medeiros, L. S., Palmeira, M., \& Cintrão, R. (2004). Impacto dos assentamentos: um estudo sobre o meio rural brasileiro. Brasília, DF: IICA/ NEAD; São Paulo: Editora Unesp.

Leite, J. F., \& Dimenstein, M. (2006). Subjetividade em movimento: o MST no Rio Grande do Norte. Psicologia \& Sociedade, 18(1), 21-30.

Núcleo de Estudos Agrários e Desenvolvimento Rural. (2006a). Estatísticas do meio rural. Brasília, DF: MDA/DIEESE.

Núcleo de Estudos Agrários e Desenvolvimento Rural. (2006b). Gênero, agricultura familiar e reforma agrária no Mercosul. Brasília, DF: MDA.

Nobre, M., Siliprandi, E., Quintela, S., \& Menasche, R. (1998). Gênero e agricultura familiar. São Paulo: SOF.

Oliveira, A. U. (1999). A geografia das lutas no campo. São Paulo: Contexto.

Organização Mundial de Saúde. (2005). Estudio multipais de la OMS sobre salud de la mujer y violencia domestica contra la mujer. Recuperado em 20 de janeiro de 2007, de www.who.int/gender/violence/who_multicountry_study/ summary report

Pavan, D. (1998). As Marias sem-terras - trajetória e experiência de vida de mulheres assentadas em Promissão-SP-1985/1996. Dissertação de Mestrado, Pontifícia Universidade Católica de São Paulo, São Paulo.

Pichon-Rivière, E. (1991). O processo grupal. São Paulo: Martins Fontes.

Programa das Nações Unidas para o Desenvolvimento/ Organização das Nações Unidas. (1997). Relatório do desenvolvimento humano. Recuperado em 13 de fevereiro de 2007, de http://www.pnud.org.br/rdh/rdh97

Silva, M. A. M. (2004). A luta pela terra. São Paulo: Editora Unesp.

Serviço de Saúde Cândido Ferreira. (2003). Entrevista com o clube dos saberes. Recuperado em 10 de julho de 2006, dewww. candido.org. $\mathrm{br} / \mathrm{html} / ?=60$

Veiga, J. E. (2003). Cidades imaginárias: o Brasil é menos urbano do que se calcula. Campinas, SP: Autores Associados. 